Article

\title{
Comparing Colorfastness to Light of Wood-Staining Fungal Pigments and Commercial Dyes: An Alternative Light Test Method for Color Fastness
}

\author{
Eric M. Hinsch * and Seri C. Robinson \\ Department of Wood Science \& Engineering, Oregon State University; Corvallis, OR 97331, USA; \\ seri.robinson@oregonstate.edu \\ * Correspondence: eric.hinsch@oregonstate.edu; Tel.: +1-541-570-7061
}

Received: 17 April 2018; Accepted: 18 May 2018; Published: 19 May 2018

\begin{abstract}
Colorfastness to light is an essential quality for textiles exposed to sunlight for a significant length of time. In this study, the colorfastness (specifically to light) of fabrics dyed with wood-staining (spalting) fungal pigments was compared to the colorfastness of commercial dyes. A short-duration immersion dying method without heat was used to minimize both water and energy usage. Both mordanted and unmordanted fabrics were tested and compared for colorfastness. Additionally, a new method of testing for colorfastness to light was developed. Results indicate that the wood-staining fungal pigments demonstrate superior colorfastness to light over commercial dyes when the employed dyeing method is used. Additionally, the colorfastness to light testing method developed using the L-2 Blue Wool Standard and QUV Accelerated Weathering Machine is a viable alternative to current standard colorfastness to light testing methods.
\end{abstract}

Keywords: fungi pigments; dyes, colorfastness; light; UV

\section{Introduction}

Colorfastness to light is an essential quality for any dye/fabric combination intended for sunlight exposure to sunlight for a significant length of time. One need only look at garments or fabric that has been in a shop display window to see that fading due to sunlight is a problem for most fabric dyes.

Textiles can be quickly and efficiently dyed with wood-staining (spalting) fungal pigments, without the use of water [1]. Spalting pigments also have unusually long persistence of color, both under laboratory conditions and in applications such as ancient marquetry and intarsia [2-4]. These characteristics indicate that spalting pigments could be more eco-friendly than commercial dyes, many of which are carcinogenic [5] and will exhibit superior colorfastness to light without the use of water or heat.

Wood-staining fungal pigments, such as xylindein and draconin red, are anthraquinones (Figures 1 and 2) [6,7], which are produced by the fungi in response to stress. Many commercial dyes, such as disperse dyes, are also anthraquinone dyes, which is one of the reason these fungal pigments were chosen for the current study. Furthermore, the ease of laboratory culturing of the fungi and extraction of the pigments make them an excellent choice for experimentation [8]. Extracted wood-staining fungal pigments have only recently been used to dye textiles, and previous tests on colorfastness to washing, perspiration, and crocking have shown promising results $[1,9,10]$. 


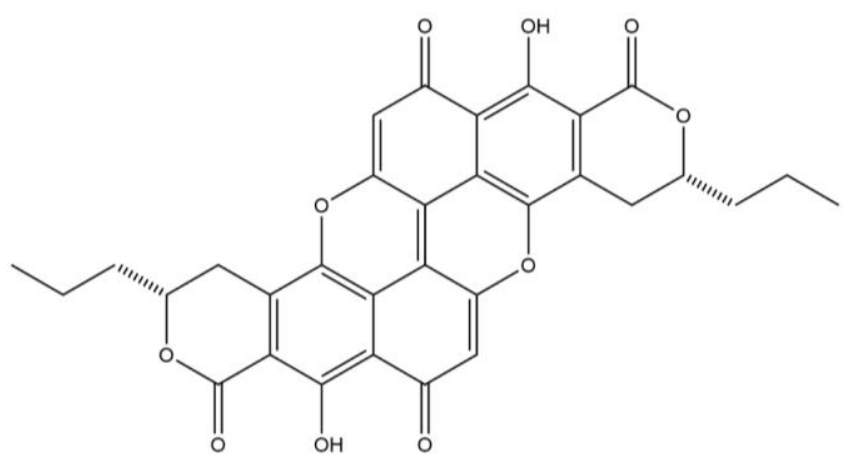

Figure 1. The structure of xylindein.

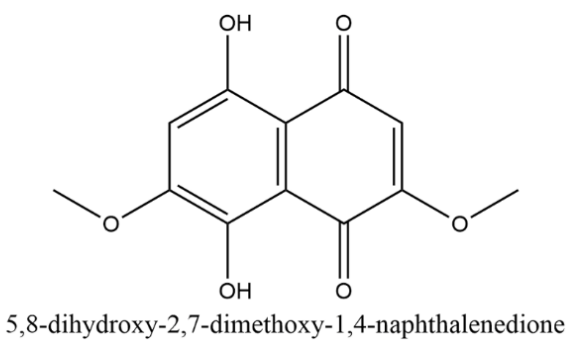

Figure 2. The only known component of draconin red.

The two most common test methods for colorfastness to light in the textiles industry are AATCC Test Method 16.3 [11] and ISO 105-B02 [12], both of which involve the use of a xenon arc lamp. If colorfastness to light testing is not a regularly performed task, the cost of a xenon arc lamp testing unit can be cost prohibitive. The same issue arises when using AATCC Test Method 16.2 [13], Colorfastness to light: Carbon arc. ISO no longer has a standard for colorfastness to light testing using a carbon arc lamp.

Two other alternatives for testing colorfastness to light are AATCC Test Method 16.1 [14], Colorfastness to light: Outdoor, and ISO 105-B01 [15], Color fastness to light: Daylight. These two methods are similar and require outdoor exposure in specially constructed frames. The ISO standard is very specific about exposure direction, shadows, grade, etc. The AATCC Test Method is less specific, but requires constant monitoring. Having the space, time, and weather conditions available to perform outdoor daylight tests on many samples may be prohibitive in regions where sunlight is limited.

In the current study, a new test method was developed as an alternative to the above methods using a QUV Accelerated Weathering Machine. The developed method requires a fraction of the time as that of outdoor daylight testing, and less exposure time than the xenon arc lamp method. Additionally, after initial calibration, monitoring is not required during testing. While more costly than simple outdoor exposure, the QUV has a wider range of functions than an arc lamp and can be used for many types of weathering tests on a variety of materials. It can be used to test reactions of fabrics, wood, and other materials to UV exposure, temperature variation, and moisture. The machine can be configured to test a variety of conditions, such as normal outdoor use or thermal shock. Its use in other testing, including another AATCC test standard, AATCC TM186 [16] therefore, may make it a more suitable machine to purchase than other UV-testing equipment.

The purpose of this study was to compare the colorfastness to light between spalting pigments and commercial dyes, without heat, using a novel, short-duration immersion dyeing method. Both unmordanted and mordanted fabrics were tested and compared for colorfastness. Noting the historic color stability of spalting pigments, it is likely that these pigments will demonstrate 
superior colorfastness (specifically in regards to light) when compared with commercial fabric dyes, using the proposed methodology.

\section{Materials and Methods}

\subsection{Materials}

\subsubsection{Fabrics}

Fabrics chosen for this study represented the most currently, commonly used textiles on the market (Table 1).

Table 1. Test fabrics.

\begin{tabular}{|c|c|c|c|c|}
\hline Fabric & Weight $\left(\mathrm{g} / \mathrm{m}^{2}\right)$ & Threads Per Inch & Structure & Genera \\
\hline $100 \%$ Cotton & 149 & $78 \times 76$ & Plain weave & Cellulosic seed \\
\hline $100 \%$ Linen & 159 & $78 \times 76$ & Plain weave & Cellulosic bast \\
\hline $100 \%$ Hemp & 254 & $34 \times 30$ & Plain weave & Cellulosic bast \\
\hline $100 \%$ Wool & 176 & $76 \times 80$ & Plain weave & Protein \\
\hline 100\% Silk & 186 & $54 \times 54$ & Plain weave & Protein \\
\hline $100 \%$ Rayon & 136 & $64 \times 38$ & Plain weave & Manufactured Regenerated \\
\hline $100 \%$ Polyester & 240 & $\mathrm{~N} / \mathrm{A}$ & Knit & Manufactured Synthetic \\
\hline
\end{tabular}

\subsubsection{Fungal Pigments}

Chlorociboria aeruginosa (strain UAMH 11657 isolate from a rotting hardwood log in Halliburton, ON, Canada), Scytalidium cuboideum (strain UAMH 11517 isolated from Quercus sp. in Memphis, TN, USA), and S. ganodermophthorum (strain UAMH 10320 isolated from oak logs used for mushroom cultivation in Gyeonggi Province, Korea) were cultured separately on sterile disposable petri plates in $2 \%$ malt agar media ( $20 \mathrm{~g}$ barley malt, $15 \mathrm{~g}$ agar, $1 \mathrm{~L}$ deionized water) mixed with approximately $2.75 \mathrm{~g}$ of sugar maple (ground to \#20 mesh, Wiley Mill, Thomas Scientific, Swedesboro, NJ, USA). Fungal cultures were taken from established cultures on $2 \%$ malt agar and recultured on the same medium. Cultures were incubated in drawers at $21{ }^{\circ} \mathrm{C}$ and $35 \% \mathrm{RH}$ for two to four months (dependent upon the fungus). C. aeruginosa produces a blue-green pigment (xylindein), S. cuboideum produces a pink-red pigment (draconin red), and S. ganodermophtherum produces a yellow pigment.

\subsubsection{Commercial Dyes}

The dye categories selected for testing (other than the fungal pigments) are commercially available, and all came from Dharma Trading Co. in Petaluma, CA, USA. Specific synthetic colors were selected to best match the spalting pigments (Table 2).

Table 2. Commercially available dyes used for testing, purchased from Dharma Trading Co., Petaluma, CA, USA.

\begin{tabular}{cccc}
\hline Dye Class & Target Fiber Type & Brand & Color \\
\hline Fiber Reactive & Cellulosic & Dharma Fiber Reactive Procion & Clear Yellow \\
Fiber Reactive & Cellulosic & Dharma Fiber Reactive Procion & Scarlet \\
Fiber Reactive & Cellulosic & Dharma Fiber Reactive Procion & Better Blue Green \\
Acid Reactive & Protein & Dharma Acid Dye & Brilliant Yellow \\
Acid Reactive & Protein & Dharma Acid Dye & Fire Engine Red \\
Acid Reactive & Protein & Dharma Acid Dye & Teal Green \\
Disperse & Synthetic & iDye for Natural and Poly Fabrics & Yellow \\
Disperse & Synthetic & iDye for Natural and Poly Fabrics & Red \\
Disperse & Synthetic & iDye for Natural and Poly Fabrics & Green \\
Natural & Cellulosic, Protein & Natural Dyes & Yellow (Osage orange) \\
Natural & Cellulosic, Protein & Natural Dyes & Red (Madder) \\
Natural & Cellulosic, Protein & Natural Dyes & Green (Spirulina) \\
\hline
\end{tabular}




\subsection{Methods}

\subsubsection{Fungal Pigment Extraction}

Forty-eight hours prior to extraction, the Parafilm was removed from the plated cultures and the tops of the plates were removed. The opened plates were placed in a fume hood to allow them to dry out. After the cultures were dry, they were broken up by hand into approximately $2 \mathrm{~cm}$ sized pieces and placed in a $250 \mathrm{~mL}$ glass round-bottomed flask. A $7.0 \mathrm{~mm} \times 24.5 \mathrm{~mm}$ octagonal magnetic stir bar was added to the flask along with $150 \mathrm{~mL}$ dichloromethane (DCM). A rubber stopper was placed on top of the flask, not inserted into it, to prevent evaporation of the DCM. The flask was then placed on a stir plate and stirred at $230 \mathrm{rpm}$ for $30 \mathrm{~min}$. After stirring, the contents of the flask were filtered through laboratory-grade Whatman No. 1002150 filter paper into a $250 \mathrm{~mL}$ glass beaker. A color reading was taken from the resultant solution on a Konica Minolta Chroma Meter CR-5, on the Liquid setting, utilizing the CIE $L^{*} a^{*} b^{*}$ color space. The target color readings are listed in Table 3 and represent $100 \%$ concentration of the pigments. If color readings did not fall within the acceptable range (Table 3), the concentration of the pigment was adjusted by either adding or evaporating off DCM as necessary. The solution was then transferred to a $1 \mathrm{~L}$ glass storage jar. This entire process was repeated until the initial $500 \mathrm{~mL}$ of pigment solution was obtained, and again to "refresh" the dye solution as needed throughout the dyeing process.

Table 3. Target color readings for fungal pigment extractions.

\begin{tabular}{ccc}
\hline Fungus & Pigment & CIE $\boldsymbol{L}^{*} \boldsymbol{a}^{*} \boldsymbol{b}^{*}$ Target \\
\hline Chlorociboria aeruginosa & Xylindein & $L^{*}=82.28, a^{*}=-11.06, b^{*}=-5.40$ \\
Scytalidium cuboideum & Draconin red & $L^{*}=82.32, a^{*}=26.84, b^{*}=13.19$ \\
Scytalidium ganodermophtherum & Unknown & $L^{*}=95.46, a^{*}=-3.00, b^{*}=-8.15$ \\
\hline
\end{tabular}

\subsubsection{Commercial Dyes}

For the fiber reactive dyes, $855 \mathrm{~mL}$ of deionized (DI) water was added to a $2000 \mathrm{~mL}$ glass beaker. To make a paste, $1.6 \mathrm{~g}$ scarlet, $0.615 \mathrm{~g}$ clear yellow, and $1.36 \mathrm{~g}$ better blue green dye powder were added to $500 \mathrm{~mL}$ glass beakers with approximately $20 \mathrm{~mL}$ of DI water. A dye slurry was made by increasing the amount of DI water to $236.5 \mathrm{~mL}$ and stirred with a glass stirring rod. The dye slurry was added to the $855 \mathrm{~mL}$ of DI water and stirred again. $66.6 \mathrm{~g}$ of non-iodized salt $(\mathrm{NaCl})$ and $5.85 \mathrm{~g}$ of soda ash (purchased from Dharma Trading Co., Petaluma, CA, USA) was added to the solution and stirred until dissolved.

For acid reactive dyes, $855 \mathrm{~mL}$ of DI water was added to a $2000 \mathrm{~mL}$ glass beaker. $0.60 \mathrm{~g}$ of each color of dye powder was added to $500 \mathrm{~mL}$ glass beakers with approximately $20 \mathrm{~mL}$ of hot $\left(82^{\circ} \mathrm{C}\right) \mathrm{DI}$ water to make a paste. A dye slurry was made by increasing the DI water to $236.5 \mathrm{~mL}$ and stirred with a glass stirring rod. The dye slurry was added to the water along with $10 \mathrm{~mL} \mathrm{5 \%}$ distilled white vinegar and stirred for $30 \mathrm{~s}$.

For disperse dyes, $855 \mathrm{~mL}$ of hot $\left(82{ }^{\circ} \mathrm{C}\right) \mathrm{DI}$ water was added to a $2000 \mathrm{~mL}$ glass beaker. $2.33 \mathrm{~g}$ of each color of dye powder was added to the DI water along with $2.3 \mathrm{~mL}$ of color intensifier (included with each packet of dye) and stirred with a glass stirring rod until the dye powder was dissolved. The beakers where covered with aluminum foil and allowed to cool to $21^{\circ} \mathrm{C}$ overnight. The dye solutions were again stirred again for $30 \mathrm{~s}$ prior to use.

For of natural dyes, $855 \mathrm{~mL}$ of DI water was heated to $82{ }^{\circ} \mathrm{C}$ in a $5.7 \mathrm{~L}$ enameled cast iron pot. To separate pots was added $9 \mathrm{~g}$ Osage orange, $8 \mathrm{~g}$ madder, and $12 \mathrm{~g}$ spirulina were and allowed to simmer, covered, for $1 \mathrm{~h}$. The suspensions were filtered through three layers of cheesecloth lining a fine mesh kitchen sieve into $1 \mathrm{~L}$ mason jars. The jars were sealed with canning lids and allowed to cool overnight to room temperature, approximately $21^{\circ} \mathrm{C}$. The dye solutions were poured into $2000 \mathrm{~mL}$ glass beakers prior to use. 


\subsection{Mordanting}

The above dyeing and the following testing procedures were repeated precisely with the same seven fabrics that had been mordanted. For mordanting, $3.8 \mathrm{~L}$ of tap water was added to an enameled iron pot, then heated to $82{ }^{\circ} \mathrm{C}$. $13.45 \mathrm{~g}$ of alum and $2.6 \mathrm{~g}$ cream of tartar (both purchased from Dharma Trading Co., California, USA) were added to the water. All the cut samples for a single fabric were added to the mordant solution. The fabric simmered in the pot, covered, at $82{ }^{\circ} \mathrm{C}$ for $1 \mathrm{~h}$. The pot was removed from the heat and the fabric was allowed to cool to $21^{\circ} \mathrm{C}$ in solution. The fabric was removed from the solution, rinsed in tap water, and the samples were laid out on garment drying racks and allowed to dry for $48 \mathrm{~h}$ at $21^{\circ} \mathrm{C}$. Dyeing and testing continued as above.

\subsubsection{Initial Rinse Test}

Prior to cutting and dyeing, all fabrics were washed in a home washing machine in approximately $49{ }^{\circ} \mathrm{C}$ tap water and $30 \mathrm{~mL}$ of textile detergent (purchased from Dharma Trading Co.) on the "regular" wash cycle. The fabrics were then tumbled dry on low for $45 \mathrm{~min}$. For initial (rinse) testing, five replicates of each fabric/dye/color combination were dyed using the short-duration immersion method without heat. Seventy-five samples of each fabric measuring $76.2 \mathrm{~mm} \times 101.6 \mathrm{~mm}$, with the warp parallel to the long dimension, were cut. For each dye type, 15 fabric samples were placed in $500 \mathrm{~mL}$ of $21{ }^{\circ} \mathrm{C}$ DI water in a $1000 \mathrm{~mL}$ glass beaker and, to assure thorough wetting and immersion, were stirred with a glass stirring rod for. The samples were allowed to soak for $15 \mathrm{~min}$.

As DCM is immiscible in water, samples to be dyed with fungal pigments were not pre-wet. Stainless steel forceps were used to remove the samples from the DI water and were placed in $2000 \mathrm{~mL}$ beakers containing dye solution. 5 samples per color were dyed at one time. To assure wetting and immersion, each dye bath was stirred with a glass stirring rod for 30 . The samples were allowed to soak for $15 \mathrm{~min}$. Stainless steel forceps were used to remove the samples from the dye solution, and the samples placed under a canopy fume hood on a drying rack constructed from standard aluminum window screening. The samples were allowed to dry for $48 \mathrm{~h}$ at $21^{\circ} \mathrm{C}$. The samples were then color read on a Konica Minolta Chroma Meter CR-5 utilizing the CIE $L^{*} a^{*} b^{*}$ color space, using the Reflectance setting with a $30 \mathrm{~mm}$ aperture. An Epson Perfection V370 Photo color scanner was used to scan all 5 replicates of each fabric/dye/color combination. After being color read and scanned, the samples were rinsed by submerging them in $1 \mathrm{~L}$ of approximately $21^{\circ} \mathrm{C}$ DI water in a $1 \mathrm{~L}$ glass beaker and agitating moderately with stainless steel forceps for $60 \mathrm{~s}$. The beaker was them emptied and refilled with clean DI water. This process was repeated until the rinse water remained clear. The samples were transferred to the previously-used drying rack and allowed to dry for $48 \mathrm{~h}$, after which they were again color read and scanned. A three-way ANOVA and Tukey HSD were run on the $\Delta E^{*}$ of the pre-rinsed and rinsed samples for each fabric type. If the $\Delta E^{*}$ was not statistically different, the fabric/dye/color combinations were used for the final test.

\subsubsection{Testing for Lightfastness}

For each fabric/dye/color combination to be tested, a $40 \mathrm{~mm}$ square was cut, maintaining a $2.54 \mathrm{~cm}$ margin from each selvedge and each end of the fabric. Five samples for each combination were cut, and the sample for each fabric were placed in separate baggies. Five samples were randomly selected from the baggies for each fabric/dye/color combination to be tested and dyed in the method as described above.

Except for those to be dyed with fungal pigments, the fabric samples were soaked in DI water for $15 \mathrm{~min}$. The samples were then dyed for $15 \mathrm{~min}$ as described previously. However, unlike the initial rinse test, the samples were immediately rinsed as described above and allowed to dry for $48 \mathrm{~h}$ at approximately $21^{\circ} \mathrm{C}$ before being color read and scanned. As DCM is immiscible in water and fungal pigments do not require rinsing, the samples dyed with fungal pigments for this test were not rinsed. 
Four samples were mounted to a $292.1 \mathrm{~mm} \times 76.2 \mathrm{~mm}$ pieces of $199 \mathrm{~g} / \mathrm{m}^{2}$ bright white cardstock with double-sided clear tape so that the samples would be in the windows of the mounting brackets of a QUV Accelerated Weathering Machine, Model QUV/spray. Each piece of cardstock containing 4 samples was mounted in the mounting brackets. The shielding doors were closed and the QUV was programmed for $14 \mathrm{~h}$ of UV-A exposure from UVA-340 lamps (365-295 nm), and a temperature of $50{ }^{\circ} \mathrm{C}$. After $14 \mathrm{~h}$ of exposure, the pieces of cardstock were unmounted and the samples were removed from the cardstock. The samples were color read and scanned on their exposed side.

The method developed in this study for testing colorfastness to light utilized a QUV Accelerated Weathering Tester. The QUV Accelerated Weathering Tester, as configured in the Computer-Aided Manufacturing Laboratory in the Department of Wood Science \& Engineering at Oregon State University, simulates sunlight with UV-340 lamps that produce UV-A light in the spectrum of 365-295 nm In order to calibrate the QUV, the AATCC L-2 Blue Wool Standard was used. The blue-dyed wool has a known fading rate. A $\Delta E^{*}$ of $3.5 \pm 0.3$ is equivalent to a gray scale level 4 color change, the standard used for fading due to natural light. Each time test was conducted using four samples of the Blue Wool Standard, cut in $40 \mathrm{~mm}$ squares. The samples were mounted in the same manner as described in the lightfastness test. The calibration test indicated that $14 \mathrm{~h}$ of exposure resulted in the appropriate $\Delta E^{*}$.

\subsection{Data Analysis}

For both the initial rinse test and the colorfastness to light test, the SpectraMagic NX CMS-S100w 2.33.0004 software used to run the Konica Minolta Chroma Meter CR-5 (Konica Minolta, Tokyo, Japan) was used to calculate $\Delta E^{*}$ utilizing the CIE $L^{*} a^{*} b^{*}$ color space. The targets were undyed samples of each fabric. A three-way ANOVA and Tukey HSD were run for each fabric and test on the model:

$$
\Delta E^{*}=\text { Dye I Color I Treatment }
$$

where Dye is the dye type (fiber reactive, acid reactive, disperse, natural, fungal pigment), Color is the dye color (yellow, red, or green), and Treatment is post-dyeing or post-testing, and $\Delta E^{*}$ is the overall change in color. Non-colorfastness was indicated by a statistical difference in $\Delta E^{*}$ between post-dyeing (a $\Delta E$ calculation of the undyed textile to the dyed textile) and post-testing (a $\Delta E$ calculation of the undyed textile to the dyed and exposed textile) for each fabric/dye/color combination.

\section{Results and Discussion}

For unmordanted fabrics tested with light, only 5 of the 30 tested fabric/dye/color combinations were colorfast: cotton/draconin red, cotton/xylindein, linen/disperse/red, wool/draconin red, and wool/disperse/red (see Table 4 and Figure 3). For mordanted fabrics tested with light, 11 of the 38 tested fabric/dye/color combinations were colorfast. Of those 11, 8 were dyed with fungal pigments, 2 with fiber reactive dyes, and one with a natural dye (spirulina) (see Table 5 and Figure 4 ). For mordanted fabrics, $p$-values for all highest possible levels of interaction were $<0.006$ at $\alpha=0.05$. For unmordanted fabrics, $p$-values for all possible highest levels of interaction were $<0.0001$ at $\alpha=0.05$, except for cotton where the $p$-value for color*treatment was 0.1396 at $\alpha=0.05$. Average $\Delta E^{*}$ values can be found in Appendix Tables A1 and A2.

The extracted fungal pigments performed better than other dyes with regards to colorfastness to light, when the short-duration immersion dyeing method was used without heat. Although there is inherently some difference between carrying a dye in water, and carrying the fungal pigments in DCM as the fungal pigments cannot be carried in water, a direct comparison was not possible. It was the authors' intent to compare a "natural" dye system to that of the fungal pigments, as these colorants will likely share a market. Hence, although different results likely would have been achieved if delivering the dyes in an organic solvent, the comparison would not have been as relevant to the end goal of this investigation. 
Table 4. Tukey HSD results for unmordanted fabrics. Highlighted rows (rows with the same letters) indicate no statistically significant difference.

\begin{tabular}{|c|c|c|c|c|}
\hline Fabric & Dye & Color & Pre-Test & Post-Test \\
\hline Silk & Acid Reactive & Green & $\mathrm{H}$ & $\mathrm{D}$ \\
\hline Wool & Acid Reactive & Green & $\mathrm{G}$ & $\mathrm{H}$ \\
\hline Wool & Acid Reactive & Red & $\mathrm{D}$ & $\mathrm{F}$ \\
\hline Wool & Acid Reactive & Yellow & B & $\mathrm{C}$ \\
\hline Cotton & Fungal Pigment & Green & B & B \\
\hline Cotton & Fungal Pigment & Red & A & A \\
\hline Hemp & Fungal Pigment & Green & B & A \\
\hline Hemp & Fungal Pigment & Red & A & $\mathrm{C}$ \\
\hline Linen & Fungal Pigment & Green & G & $\mathrm{E}$ \\
\hline Linen & Fungal Pigment & Red & $\mathrm{F}$ & $\mathrm{E}, \mathrm{F}$ \\
\hline Polyester & Fungal Pigment & Green & $\mathrm{D}$ & B \\
\hline Polyester & Fungal Pigment & Red & $\mathrm{C}$ & A \\
\hline Rayon & Fungal Pigment & Green & $\mathrm{F}$ & $\mathrm{C}$ \\
\hline Rayon & Fungal Pigment & Red & E & $\mathrm{D}$ \\
\hline Silk & Fungal Pigment & Green & $\mathrm{L}$ & $\mathrm{G}$ \\
\hline Silk & Fungal Pigment & Red & $\mathrm{K}$ & $\mathrm{B}$ \\
\hline Wool & Fungal Pigment & Green & $\mathrm{J}$ & I \\
\hline Wool & Fungal Pigment & Red & I & I \\
\hline Linen & Disperse & Red & C & C, D \\
\hline Linen & Disperse & Yellow & $\mathrm{E}$ & $\mathrm{D}$ \\
\hline Silk & Disperse & Red & E & $\mathrm{G}, \mathrm{H}$ \\
\hline Silk & Disperse & Yellow & I & $\mathrm{J}$ \\
\hline Wool & Disperse & Red & $\mathrm{F}$ & $\mathrm{H}$ \\
\hline Linen & Fiber Reactive & Green & A & B \\
\hline Rayon & Fiber Reactive & Green & A & B \\
\hline Silk & Fiber Reactive & Green & A & M \\
\hline Silk & Fiber Reactive & Red & $\mathrm{F}$ & $\mathrm{L}$ \\
\hline Silk & Fiber Reactive & Yellow & $\mathrm{C}$ & K \\
\hline Wool & Fiber Reactive & Red & A & $\mathrm{B}$ \\
\hline Wool & Fiber Reactive & Yellow & E & $\mathrm{F}$ \\
\hline \multicolumn{2}{|c|}{ Unmordanted } & Pre-Test & \multicolumn{2}{|c|}{ Post-Test } \\
\hline \multicolumn{5}{|c|}{ Cotton/Xylindein } \\
\hline \multicolumn{2}{|c|}{ Cotton/Draconin Red } & $\frac{x}{x^{4}+3}$ & & \\
\hline \multicolumn{5}{|c|}{ Polyester/Xylindein } \\
\hline \multicolumn{2}{|c|}{ Polyester/Draconin Red } & & & \\
\hline
\end{tabular}

Figure 3. Examples of pre- and post-tested unmordanted fabrics dyed with fungal pigments. 
Table 5. Tukey HSD results for mordanted fabrics. Highlighted rows (rows with the same letters) indicate no statistically significant difference.

\begin{tabular}{|c|c|c|c|c|}
\hline Fabric & Dye & Color & Pre-Test & Post-Test \\
\hline Silk & Acid Reactive & Green & $\mathrm{F}$ & G \\
\hline Silk & Acid Reactive & Red & B & $\mathrm{D}$ \\
\hline Silk & Acid Reactive & Yellow & A & $\mathrm{C}$ \\
\hline Wool & Acid Reactive & Red & C & $\mathrm{E}$ \\
\hline Wool & Acid Reactive & Yellow & C, D & $\mathrm{E}$ \\
\hline Cotton & Fungal Pigment & Green & $\mathrm{J}$ & J \\
\hline Cotton & Fungal Pigment & Red & G & $\mathrm{H}$ \\
\hline Cotton & Fungal Pigment & Yellow & I & $\mathrm{J}$ \\
\hline Hemp & Fungal Pigment & Green & $\mathrm{D}$ & $\mathrm{B}, \mathrm{C}, \mathrm{D}$ \\
\hline Hemp & Fungal Pigment & Red & $\mathrm{B}, \mathrm{C}$ & C, D \\
\hline Hemp & Fungal Pigment & Yellow & B, C & B, C \\
\hline Linen & Fungal Pigment & Green & $\mathrm{F}$ & E \\
\hline Polyester & Fungal Pigment & Green & A & $\mathrm{C}$ \\
\hline Polyester & Fungal Pigment & Red & A & B \\
\hline Rayon & Fungal Pigment & Green & $\mathrm{E}$ & C, D \\
\hline Silk & Fungal Pigment & Green & K & $\mathrm{J}, \mathrm{K}$ \\
\hline Silk & Fungal Pigment & Red & I & $\mathrm{I}, \mathrm{J}$ \\
\hline Wool & Fungal Pigment & Green & I & $\mathrm{H}, \mathrm{I}$ \\
\hline Wool & Fungal Pigment & Yellow & $\mathrm{H}, \mathrm{I}$ & $\mathrm{H}$ \\
\hline Silk & Disperse & Red & $\mathrm{D}$ & G \\
\hline Wool & Disperse & Red & $\mathrm{D}, \mathrm{E}$ & G \\
\hline Cotton & Fiber Reactive & Green & $\mathrm{D}$ & $\mathrm{F}$ \\
\hline Cotton & Fiber Reactive & Red & A & B \\
\hline Cotton & Fiber Reactive & Yellow & $\mathrm{C}$ & $\mathrm{E}$ \\
\hline Hemp & Fiber Reactive & Green & A & $\mathrm{D}$ \\
\hline Hemp & Fiber Reactive & Yellow & A & A \\
\hline Linen & Fiber Reactive & Green & $\mathrm{C}$ & $\mathrm{D}$ \\
\hline Linen & Fiber Reactive & Red & A & B \\
\hline Rayon & Fiber Reactive & Green & $\mathrm{C}$ & $\mathrm{D}, \mathrm{E}$ \\
\hline Rayon & Fiber Reactive & Red & A & B \\
\hline Silk & Fiber Reactive & Green & $\mathrm{H}$ & I \\
\hline Silk & Fiber Reactive & Red & $\mathrm{E}$ & G \\
\hline Silk & Fiber Reactive & Yellow & $\mathrm{H}$ & $\mathrm{H}$ \\
\hline Wool & Fiber Reactive & Red & B & $\mathrm{E}$ \\
\hline Wool & Fiber Reactive & Yellow & $\mathrm{F}$ & $\mathrm{F}, \mathrm{G}$ \\
\hline Cotton & Natural & Green & J & $\mathrm{J}$ \\
\hline Wool & Natural & Red & $\mathrm{D}, \mathrm{E}$ & $\mathrm{F}$ \\
\hline Wool & Natural & Yellow & A & C, D \\
\hline & lordanted & Pre-Test & \multicolumn{2}{|c|}{ Post-Test } \\
\hline \multicolumn{2}{|c|}{ Cotton/Xylindein } & & \multicolumn{2}{|c|}{ 8. } \\
\hline \multicolumn{3}{|c|}{ Cotton/Yellow Pigment } & \multicolumn{2}{|c|}{$8=8$} \\
\hline \multicolumn{5}{|c|}{ Polyester/Xylindein } \\
\hline & ter/Draconin Red & & & \\
\hline
\end{tabular}

Figure 4. Examples of pre- and post-tested mordanted fabrics dyed with fungal pigments. 
Draconin red performed better than xylindein, at least for unmordanted fabrics, although no fabric or dye/color was outstanding. Due to xylindein's characteristically persistent nature on wood [2,3], even after centuries, it would have been expected that the pigment would have demonstrated better colorfastness to light. It is UV radiation that causes color fading by inducing a chemical reaction that breaks the carbon-carbon double bonds of quinone-based pigments [17]. It may be that xylindein binds to certain fibers in such a way as to prevent this chemical reaction yet binds differently in other fibers allowing the chemical reaction to occur. This could explain why some of the fabrics dyed with xylindein were colorfast to light while others were not.

Examination of clothing, fabric, or yarn that has been in a shop display window will show that fading due to exposure to sunlight is a problem with most dyes. With mordanted fabrics dyed with fungal pigments, colorfastness to light was about 1.5 times greater than that of unmordanted fabrics dyed with fungal pigments ( $21 \%$ of samples compared to $13 \%$ of samples). This indicates that mordanting may improve colorfastness to light, especially with the fungal pigments.

Every fungal pigment sample on unmordanted fabrics that was colorfast to light was also colorfast when mordanted, with the exception of cotton/draconin red, and five additional fabrics dyed with fungal pigments were colorfast to light when mordanted. Why colorfastness did not function as well with cotton and draconin red is unknown, however it may have something to do with the unique crystalline nature of the draconin red pigment [18]. Mordanting improved colorfastness to light on cotton, hemp, silk, and wool. In three recent studies, that included testing for colorfastness to light for silk, cotton, and nylon colored with natural dyes, mordanting had variable effects on lightfastness. In the Haar et al. study [19], aluminum-based mordants did not affect colorfastness to light of cotton dyed with madder or weld, and slightly decreased the colorfastness to light of cotton dyed with coreopsis (AATCC Test Method 16.3). In the Shams-Nateri et al. study [20] of aluminum potassium sulfate $\left(\mathrm{AlK}\left(\mathrm{SO}_{4}\right)_{2}\right)$ mordanted nylon dyed with weld and pomegranate peel, colorfastness to light was decreased for weld except when the samples were post-mordanted (mordanted after dyeing). Colorfastness to light for nylon dyed with pomegranate peel increased except when the samples were meta-mordanted (mordanted at the same time they were dyed) (ISO 105-B02).

In the Punrattanasin et al. study [21] on silk dyed with mangrove bark extract, aluminum potassium sulfate had no effect on colorfastness to light, ferrous sulfate and copper (II) sulfate $\left(\mathrm{CuSO}_{4}\right)$ increased colorfastness to light, and stannous chloride $\left(\mathrm{SnCl}_{2}\right)$ decreased colorfastness to light (ISO 105-B02). The inconsistency of the results from these studies compared with the results of the current study indicates that, at least for the alum and cream of tartar mordant, mordanting yields more consistent colorfastness to light results for fungal pigments, especially on natural fibers. None of the fungal pigments / fabric combinations exhibited a decreased colorfastness to light when mordanted (excluding cotton/draconin red), and a few combinations exhibited increased colorfastness.

A general statement cannot be made as to whether mordanting improves, does not change, or decreases colorfastness to light for natural dyes. Results are heavily dependent on dye type, mordant type, and fiber type. Despite the apparent improvement of colorfastness to light of fungal pigments when used on mordanted fabrics, fungal pigments may require a UV-protective finish (such as those used on woodworks to prevent UV degradation, or those used on the red-stained boxelder wood to prevent degradation of the tree-red pigment) if the end use of the textile requires prolonged exposure to sunlight.

\section{Conclusions}

Extracted fungal pigments were more colorfast to light than any of the other dyes tested when using the short-duration immersion dyeing method without heat. Only $13-28 \%$ of the samples tested were colorfast to light, even with mordanting. A UV-protective coating would be necessary to prevent color loss if fungal pigment-dyed textiles were to be used in an environment which required extensive exposure to daylight. 
Using the L-2 Blue Wool Standard for preliminary calibration, it was possible to use a QUV Accelerated Weathering Machine with UVA-340 lamps to perform simulated sunlight testing. Both the decreased amount of time and the elimination of meta-test monitoring required by current outdoor daylight standards make the QUV method more efficient. The ability to use existing equipment to perform colorfastness to light testing eliminated the need to purchase expensive equipment for a single study. Calibration with the L-2Blue Wool standard may provide a means to conduct simulated daylight testing for fabric dyes on any simulated-daylight equipment.

Author Contributions: These authors contributed equally to this work.

Funding: This research received no external funding

Acknowledgments: The authors would like to acknowledge the support and expertise of Hsiou-Lien Chen with this research.

Conflicts of Interest: The authors declare no conflict of interest.

\section{Appendix A}

Table A1. Average $\Delta E^{*}$ for unmordanted fabrics pre- and post-test. $\Delta E^{*}$ is calculated using undyed fabric as a reference. $\mathrm{AR}=$ acid reactive dye, $\mathrm{FP}=$ fungal pigment, $\mathrm{ID}=$ disperse dye, $\mathrm{MX}=$ fiber reactive dye.

\begin{tabular}{|c|c|c|c|c|}
\hline Fabric & Dye Type & Color & Pre-Test $\Delta E^{*}$ & Post-Test $\Delta E^{*}$ \\
\hline Cotton & $\mathrm{FP}$ & Green & 1.27 & 1.15 \\
\hline Cotton & FP & Red & 4.81 & 3.90 \\
\hline Hemp & $\mathrm{FP}$ & Green & 3.66 & 2.82 \\
\hline Hemp & $\mathrm{FP}$ & Red & 5.64 & 5.10 \\
\hline Linen & FP & Green & 1.15 & 6.19 \\
\hline Linen & $\mathrm{FP}$ & Red & 4.30 & 5.38 \\
\hline Linen & ID & Red & 13.24 & 12.50 \\
\hline Linen & ID & Yellow & 6.12 & 11.43 \\
\hline Linen & MX & Green & 26.91 & 24.37 \\
\hline Polyester & $\mathrm{FP}$ & Green & 2.35 & 10.45 \\
\hline Polyester & $\mathrm{FP}$ & Red & 7.88 & 11.58 \\
\hline Rayon & $\mathrm{FP}$ & Green & 1.56 & 4.78 \\
\hline Rayon & $\mathrm{FP}$ & Red & 2.64 & 4.03 \\
\hline Rayon & MX & Green & 21.33 & 19.32 \\
\hline Silk & AR & Green & 28.07 & 43.99 \\
\hline Silk & $\mathrm{FP}$ & Green & 2.44 & 30.20 \\
\hline Silk & $\mathrm{FP}$ & Red & 5.11 & 47.91 \\
\hline Silk & ID & Red & 34.61 & 29.06 \\
\hline Silk & ID & Yellow & 14.57 & 6.53 \\
\hline Silk & MX & Green & 49.41 & 0.86 \\
\hline Silk & $\mathrm{MX}$ & Red & 32.17 & 3.20 \\
\hline Silk & $\mathrm{MX}$ & Yellow & 46.41 & 6.53 \\
\hline Wool & $\mathrm{AR}$ & Green & 11.93 & 10.72 \\
\hline Wool & AR & Red & 17.72 & 14.98 \\
\hline Wool & $\mathrm{AR}$ & Yellow & 21.47 & 19.23 \\
\hline Wool & $\mathrm{FP}$ & Green & 0.73 & 1.53 \\
\hline Wool & $\mathrm{FP}$ & Red & 2.06 & 2.21 \\
\hline Wool & ID & Red & 15.14 & 10.79 \\
\hline Wool & $M X$ & Red & 25.21 & 21.73 \\
\hline Wool & MX & Yellow & 16.61 & 15.42 \\
\hline
\end{tabular}


Table A2. Average $\Delta E^{*}$ for mordanted fabrics pre- and post-test. $\Delta E^{*}$ is calculated using undyed fabric as a reference. $\mathrm{AR}=$ acid reactive dye, $\mathrm{FP}=$ fungal pigment, $\mathrm{ID}=$ disperse dye, $\mathrm{MX}=$ fiber reactive dye, $\mathrm{NT}=$ natural dye.

\begin{tabular}{|c|c|c|c|c|}
\hline Fabric & Dye Type & Color & Pre-Test $\Delta E^{*}$ & Post-Test $\Delta E^{*}$ \\
\hline Cotton & FP & Red & 7.34 & 3.90 \\
\hline Cotton & FP & Green & 2.15 & 1.88 \\
\hline Cotton & FP & Yellow & 22.58 & 1.90 \\
\hline Cotton & MX & Red & 33.67 & 27.01 \\
\hline Cotton & MX & Green & 19.97 & 14.61 \\
\hline Cotton & MX & Yellow & 22.77 & 17.70 \\
\hline Cotton & NT & Green & 1.39 & 2.16 \\
\hline Hemp & FP & Red & 7.29 & 6.06 \\
\hline Hemp & $\mathrm{FP}$ & Green & 5.22 & 6.38 \\
\hline Hemp & FP & Yellow & 7.14 & 6.76 \\
\hline Hemp & MX & Green & 11.74 & 5.57 \\
\hline Hemp & MX & Yellow & 12.59 & 11.80 \\
\hline Linen & FP & Green & 7.38 & 10.38 \\
\hline Linen & MX & Red & 30.42 & 24.72 \\
\hline Linen & $\mathrm{MX}$ & Green & 21.46 & 17.31 \\
\hline Polyester & $\mathrm{FP}$ & Red & 8.03 & 12.27 \\
\hline Polyester & $\mathrm{FP}$ & Green & 4.41 & 12.17 \\
\hline Rayon & FP & Green & 9.57 & 10.83 \\
\hline Rayon & MX & Red & 25.90 & 21.93 \\
\hline Rayon & MX & Green & 11.95 & 10.42 \\
\hline Silk & ID & Red & 27.20 & 18.53 \\
\hline Silk & MX & Green & 7.47 & 5.19 \\
\hline Silk & MX & Red & 23.96 & 17.12 \\
\hline Silk & MX & Yellow & 7.56 & 7.31 \\
\hline Silk & $\mathrm{AR}$ & Green & 21.81 & 18.18 \\
\hline Silk & AR & Red & 32.85 & 27.47 \\
\hline Silk & $\mathrm{AR}$ & Yellow & 36.87 & 30.33 \\
\hline Silk & $\mathrm{FP}$ & Green & 1.94 & 2.92 \\
\hline Silk & $\mathrm{FP}$ & Red & 5.29 & 4.58 \\
\hline Wool & NT & Yellow & 22.89 & 16.65 \\
\hline Wool & NT & Red & 15.44 & 12.02 \\
\hline Wool & ID & Red & 15.71 & 10.34 \\
\hline Wool & MX & Red & 20.08 & 15.08 \\
\hline Wool & MX & Yellow & 12.79 & 11.42 \\
\hline Wool & $\mathrm{AR}$ & Yellow & 16.75 & 14.35 \\
\hline Wool & $\mathrm{AR}$ & Red & 17.94 & 14.73 \\
\hline Wool & $\mathrm{FP}$ & Green & 2.18 & 4.00 \\
\hline Wool & FP & Yellow & 2.78 & 3.49 \\
\hline
\end{tabular}

\section{References}

1. Weber, G.; Chen, H.L.; Hinsch, E.; Freitas, S.; Robinson, S. Pigments extracted from the wood-staining fungi Chlorociboria aeruginosa, Scytalidium cuboideum, and S. ganodermophthorum show potential for use as textile dyes. Color. Technol. 2014, 130, 445-452. [CrossRef]

2. Blanchette, R.A.; Wilmering, A.M.; Baumeister, M. The use of green-stained wood caused by the fungus Chlorociboria in intarsia masterpieces from the 15th-century. Holzforschung 1992, 46, 225-232. [CrossRef]

3. Michaelsen, H.; Unger, A.; Fischer, C.-H. Blaugrüne färbung an intarsienhölzern des 16. Bis 18. Jahrhunderts: Wie kann sie identifiziert werden? Restauro 1992, 98, 17-25.

4. Robinson, S.C.; Hinsch, E.; Weber, G.; Freitas, S. Method of extraction and resolubilisation of pigments from Chlorociboria aeruginosa and Scytalidium cuboideum, two prolific spalting fungi. Color. Technol. 2014, 130, 221-225. [CrossRef]

5. Slater, K. Environmental Impact of Textiles: Production, Processes and Protection; Woodhead Publishing: Cambridge, UK, 2003; Volume 27. 
6. Golinski, P.; Krick, T.P.; Blanchette, R.A.; Mirocha, C.J. Chemical characterization of a red pigment (5,8-dihydroxy-2,7-dimethoxy-1,4-napthalenedione) produced by Arthrographis cuboidea in pink stained wood. Holzforschung 1995, 49, 407-410. [CrossRef]

7. Saikawa, Y.; Watanabe, T.; Hashimoto, K.; Nakata, A. Absolute configuration and tautomeric structure of xylindein, a blue-green pigment of Chlorociboria species. Phytochemistry 2000, 55, 237-240. [CrossRef]

8. Robinson, S.C.; Tudor, D.; Snider, H.; Cooper, P.A. Stimulating growth and xylindein production of Chlorociboria aeruginascens in agar-based systems. AMB Express 2012, 2, 15. [CrossRef] [PubMed]

9. Hinsch, E.M.; Weber, G.; Chen, H.-L.; Robinson, S.C. Colorfastness of extracted wood-staining fungal pigments on fabrics: A new potential for textile dyes. J. Text. Appar. Technol. Manag. 2015, 9, 1-11.

10. Hinsch, E.M.; Robinson, S.C. Mechanical color reading of wood-staining fungal pigment textile dyes: An alternative method for determining colorfastness. Coatings 2016, 6, 25. [CrossRef]

11. Aatcc Test Method 16.3: Colorfastness to Light: Xenon Arc; American Association of Textile Chemists and Colorists (AATCC): Research Triangle Park, NC, USA, 2012.

12. ISO 105-B02:2014 Textiles—Tests for Colour Fastness_Part b02: Colour Fastness to Artificial Light: Xenon Arc Fading Lamp Test; ISO: Geneva, Switzerland, 2014.

13. Aatcc Test Method 16.2-2012: Colorfastenss to Light: Carbon Arc; American Association of Textile Chemists and Colorists (AATCC): Research Triangle Park, NC, USA, 2012.

14. Aatcc Test Method 16.1-2012: Colofastness to Light: Outdoor; American Association of Textile Chemists and Colorists (AATCC): Research Triangle Park, NC, USA, 2012.

15. ISO 105-B01:2014 Textiles—Tests for Colour Fastness_Part b01: Colour Fastness to Light: Daylight; ISO: Geneva, Switzerland, 2014.

16. Aatcc Test Method 186 Weather Reistance: UV Light and Moisture Exposure; American Association of Textile Chemists and Colorists (AATCC): Research Triangle Park, NC, USA, 2013.

17. Nassau, K. The physics and chemistry of color: The fifteen causes of color. In The Physics and Chemistry of Color: The Fifteen Causes of Color, 2nd ed.; Nassau, K., Ed.; Wiley-VCH: Weinheim, Germany, 2001; Volume 1, p. 496, ISBN 0-471-39106-9.

18. Vega Gutierrez, S.M.; Hazell, K.K.; Simonsen, J.; Robinson, S.C. Pigment used in ancient marquetry technique contains a novel organic naphthoquinone crystal. Mycologia 2018, submitted.

19. Haar, S.; Schrader, E.; Gatewood, B.M. Comparison of aluminum mordants on the colorfastness of natural dyes on cotton. Cloth. Text. Res. J. 2013, 31, 97-108. [CrossRef]

20. Shams-Nateri, A.; Hajipour, A.; Dehnavi, E.; Ekrami, E. Colorimetric study on polyamides dyeing with weld and pomegranate peel natural dyes. Cloth. Text. Res. J. 2014, 32, 124-135. [CrossRef]

21. Punrattanasin, N.; Nakpathom, M.; Somboon, B.; Narumol, N.; Rungruangkitkrai, N.; Mongkholrattanasit, R. Silk fabric dyeing with natural dye from mangrove bark (Rhizophora apiculata Blume) extract. Ind. Crop. Prod. 2013, 49, 122-129. [CrossRef]

(C) 2018 by the authors. Licensee MDPI, Basel, Switzerland. This article is an open access article distributed under the terms and conditions of the Creative Commons Attribution (CC BY) license (http://creativecommons.org/licenses/by/4.0/). 